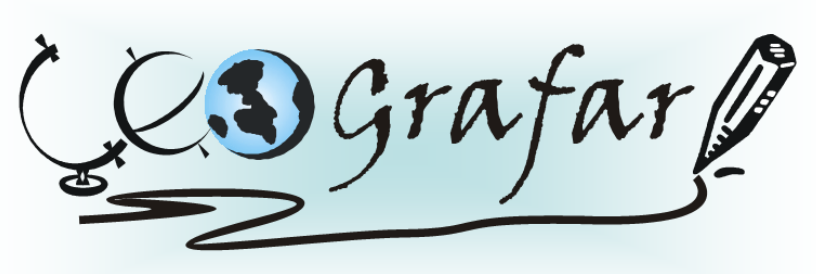

Revista Eletrônica do Programa de Pós-Graduação em Geografia - UFPR

\title{
CONFLITOS SOCIOAMBIENTAIS NO CAMPO EM APODI-RN: CONTRIBUIÇÕES PROPOSITIVAS DA CARTOGRAFIA SOCIAL
}

\section{CONFLICT IN THE ENVIRONMENTAL FIELD IN APODI-RN: PROPOSITIONAL CONTRIBUTIONS OF SOCIAL CARTOGRAPHY}

\author{
Brenda Thais Galdino da Rocha \\ Graduanda em Geografia \\ Universidade Federal do Ceará \\ Fortaleza, CE, Brasil \\ e-mail: brendatgaldinor@gmail.com \\ Francisco Otávio Landim Neto \\ Prof. MSc. do curso de Geografia \\ Universidade Federal do Amapá \\ Oiapoque, AP, Brasil \\ e-mail: otaviogeo@oi.com.br

\section{Antônio Jeovah de Andrade Meireles Prof. Dr. do curso de Geografia Universidade Federal do Ceará \\ Fortaleza, CE, Brasil e-mail:meireles@ufc.com} \\ Adryane Gorayeb \\ Prof $^{-}$Dr $^{-a}$ do Departamento de Geografia \\ Universidade Federal do Ceará \\ Fortaleza CE, Brasil \\ e-mail: gorayeb@ufc.com
}

\section{RESUMO}

A Cartografia Social afigura-se em um importante procedimento metodológico voltado para a construção do conhecimento territorial a partir da valorização dos múltiplos saberes dos sujeitos sociais. Este artigo objetiva tecer uma teorização baseada em práticas voltadas à construção de mapeamentos sociais por agricultores e agricultoras do Município de Apodi - RN sendo elencados um conjunto de conflitos socioambientais vivenciados no território. Os procedimentos metodológicos tiveram referencial teórico fundamentado nos estudos de Gorayeb, Meireles, Silva (2015); Bargas, Cardoso, (2015); Cubides (2009), dentre outros, 
onde os procedimentos técnicos consistiram na utilização da técnica de overlay para a elaboração dos mapas sociais. Diante do exposto pode-se afirmar que, i) a Cartografia Social propiciou o aprofundamento no reconhecimento das características, conflitos, problemas e proposições voltadas à garantia de direitos sociais das diferentes regiões existentes no município de Apodi, ii) houve a fortificação das relações comunitárias durante as atividades voltadas à formação geocartogáfica e, iii) foi perceptível integração entre os saberes populares e o conhecimento cientifico que culminaram na construção dos mapas sociais sob 0 prisma da coletividade.

Palavras-chave: Cartografia Social; Conflitos Sociambientais; Apodi.

\begin{abstract}
The Social Cartography appears in an important methodological approach toward the construction of territorial knowledge from the valuation of multiple knowledge of social subjects. This article aims to weave a theory based on practices aimed at building social mapping by farmers in the city of Apodi - RN, being listed a set of socio-environmental conflicts experienced in the territory. The methodological procedures were based on theoretical studies by Gorayeb, Meireles, Silva (2015); Bargas, Cardoso, (2015); Cubides (2009), among others, in which the technical procedures consisted of using the overlay technique for the preparation of social maps. Given the above it can be said that, I) the Social Cartography led deepening the recognition of features, conflicts, problems and proposals aimed at ensuring social rights of the different existing areas in the city of Apodi, II) there was the fortification of community relations during activities aimed at geocartographic training and III) it was noticeable integration between popular knowledge and scientific knowledge that led to the construction of social maps from the perspective of the community.
\end{abstract}

Keywords: Social Cartography; Socio-Environmental Conflicts; Apodi.

\title{
INTRODUÇÃO
}

O conhecimento das características inerentes ao território afigura-se de extrema relevância para que seja possível pensar em ações voltadas ao planejamento e gestão dos sistemas ambientais. As práticas relacionadas à Cartografia Social estão voltadas a esse contexto de propiciar o empoderamento de sujeitos sociais mediante a representação do território em suas diversas dimensões, a saber, social, ambiental, econômica, simbólica, além de oportunizar a visibilização de conflitos sociais. 
É nesse contexto que este artigo objetiva realizar apontamentos teóricos revelados desde as práticas voltadas ao mapeamento construído por agricultores e agricultoras do Município de Apodi/RN. As representações cartográficas dos sistemas ambientais do território de domínio das práticas camponesas iniciaram com a sistematização dos conflitos socioambientais vivenciados no campo, culminando com as ações propositivas voltadas à garantia dos direitos sociais e melhoria da qualidade de vida da população que vive no campo.

As ações metodológicas realizadas durante as atividades concernentes à Cartografia Social foram baseadas na investigação-ação-participação. Dessa forma, procurou-se atingir a integração entre os saberes populares e o conhecimento da Ciência Cartográfica materializados através da construção dos mapas de seus territórios tradicionais elaborados pelos sujeitos sociais.

\section{PROCEDIMENTOS METODOLÓGICOS}

\section{Referencial Teórico}

A Cartografia Social é uma proposta metodológica da Ciência Cartográfica que busca valorizar o conhecimento tradicional, popular, simbólico e cultural mediante as ações de mapeamento de territórios tradicionais, étnicos e coletivos (GORAYEB, MEIRELES, SILVA, 2015).

A proposta metodológica de construção social e participativa é o princípio básico da Cartografia Social, que se materializa pela construção espacial de conflitos e representações afirmativas, buscando, a partir da elaboração de mapas, instrumentalizar a luta social e comunitária dos referidos grupos.

Os métodos participativos utilizados nas cartografias com comunidades locais podem realizar a integração de múltiplas escalas, local, regional e nacional (conforme a abrangência de determinado conflito existente), sendo importante no processo de confecção da CS a ação protagonista dos sujeitos mapeadores (BARGAS, CARDOSO, 2015). Conforme Acselrad; Coli (2008) vários métodos e ferramentas participativas, a saber, cartografia efêmera; cartografia de esboço; cartografia de escala; modelagem 3D, foto-mapa; GPS; sistema multimídia de 
informações vinculados a mapas que auxiliam a C.S são usados e disseminados mundialmente.

De acordo com Popayan (2005), enquanto aporte metodológico a Cartografia Social possui fundamentos na investigação-ação-participação baseados no território como elementos fundamentais no processo de elaboração coletiva dos mapas. Dessa forma, as práticas de pesquisa acadêmica são realizadas de modo a contribuir diretamente com as demandas sociais, envolvendo o pesquisador nas articulações comunitárias por justiça social e ambiental e para contribuir na resolução de problemas associados com os conflitos (Albry, 2011).

A Cartografia Social funciona, então, como uma ferramenta para intervenção baseada no trabalho de identificação de categorias, variáveis e indicadores, a fim de proporcionar os primeiros procedimentos para organização das informações e compor um banco de dados. Faz-se necessário definir a ação, os objetivos, e a escala (nível local, regional, nacional) de trabalho. A partir do aporte metodológico (investigação, ação, participação e sistematização), a Figura 1 apresenta um organograma relacionando a CS e aos fundamentos da investigação participativa.

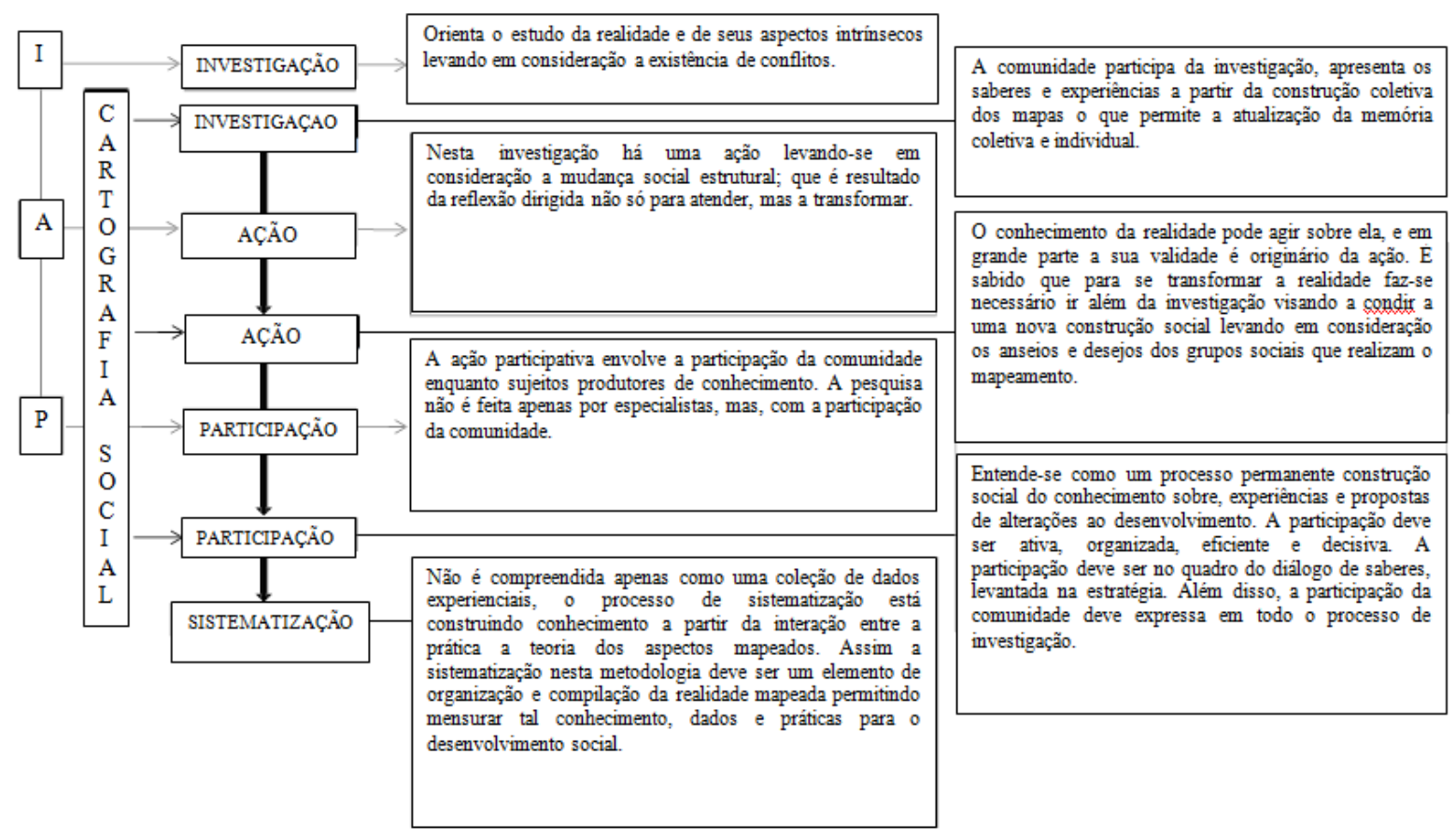

Figura 1 - Organograma da Cartografia Social e os fundamentos da investigação participativa. 


\section{Procedimentos Técnicos}

O trabalho foi desenvolvido a partir do compartilhamento dos saberes tradicionais (trabalhadores e trabalhadoras rurais do município de Apodi - Rio Grande do Norte) auxiliados pelo conhecimento científico (equipe do Laboratório de Geoprocessamento-LABOCART do Departamento de Geografia da Universidade Federal do Ceará). Tal partilha, deu-se em torno da construção de mapas que visibilizaram os problemas e conflitos presentes do território. O processo de construção política da Cartografia Social (CS) deu-se por meio de cinco etapas essenciais, a saber:

- Diagnóstico: As ações referentes ao diagnóstico corresponderam ao mecanismo introdutório de aproximação que permitiu a partilha das situações presentes no território. O diagnóstico ocorreu a partir da construção de debates críticos acerca das problemáticas presentes no território.

- Formação: Uma das intenções principais na construção de mapeamentos sociais é a transferência dialógica entre os saberes, portanto, um momento essencial para essa construção são os momentos de capacitação para com as comunidades envolvidas, visto a importância de aproximação com os princípios básicos da Ciência Cartográfica.

- Elaboração dos mapas: O processo de elaboração dos mapas sociais deuse inicialmente por meio da utilização de elementos primordiais da cartografia, a exemplo, as imagens de satélite e sistemas globais de orientação, como grade de coordenadas, escala (preferencialmente gráfica) e norte geográfico. Elenca-se a importância da construção das feições e legendas representando as informações geradas pelos sujeitos sociais que participaram do mapeamento. A técnica utilizada correspondeu ao overlay que corresponde a sobreposição de folhas de papel vegetal às imagens de satélite com os limites do território em questão.

- Sistematização: Após a confecção das representações nas imagens trabalhadas ocorreu as ações voltadas a sistematização as informações produzidas. Tal etapa ocorreu nas dependências no Laboratório de Geoprocessamento, com a utilização do Sistema de Informação Geográfica Livre (QGIS 2.8) onde deu-se a transposição das informações mapeadas para o referido sistema de informação mediante a utilização de três entidades, ponto, linha e polígono sendo possível a 
realização da digitalização das informações mapeadas o que forneceu a validade e padronização dos mapas feitos pelos agricultores e agricultoras no município de Apodi.

- Avaliação: Acredita-se que a avaliação foi um momento de fundamental importância na construção dos mapas, correspondeu à reflexão sobre o processo, os produtos e as expectativas sobre todo o processo de formação inerente a Cartografia Social. Foram estabelecidos momentos abertos de debates, onde as considerações dos sujeitos produtores foram levadas em consideração. O Quadro 1 apresenta a descrição das etapas de elaboração dos mapas, objetivos, metas alcançadas e imagem.

\begin{tabular}{|c|c|c|c|}
\hline Etapa & Objetivo & Meta Alcançada & Imagem \\
\hline Diagnóstico & $\begin{array}{l}\text { Compreender as problemáticas } \\
\text { socioambientais presentes no território. }\end{array}$ & $\begin{array}{l}\text { Debates críticos e visitas em campo } \\
\text { promovendo or reconhecimento } \\
\text { empírico das problemáticas. }\end{array}$ & \\
\hline Formação & $\begin{array}{lcc}\text { Transferência dialógica } & \text { entre } \\
\text { tecnologias e saberes. } & \end{array}$ & $\begin{array}{l}\text { Capacitação - cartográfica e política - } \\
\text { a fim do reconhecimento de elementos } \\
\text { básicos da Cartografia e as dimensões } \\
\text { sociais que ela vem alcançando. }\end{array}$ & \\
\hline Construção & $\begin{array}{l}\text { Sistematizar espacialmente as } \\
\text { informações e reivindicações inerentes } \\
\text { ao território pelos atores sociais que } \\
\text { vivem e residem neste. }\end{array}$ & $\begin{array}{l}\text { Construção dos mapas sociais das } \\
\text { regiões de Apodi - RN }\end{array}$ & \\
\hline Sistematização & $\begin{array}{lll}\text { Padronizar } & \text { cartograficamente } & \text { os } \\
\text { sociomapas. } & & \end{array}$ & $\begin{array}{l}\text { Produtos cartográficos legítimos e } \\
\text { formalmente sistematizados. }\end{array}$ & \\
\hline Avaliação & $\begin{array}{l}\text { Compreender a relevância e } \\
\text { aplicabilidade que os grupos sociais } \\
\text { mapeadores, enxergam no processo e } \\
\text { produtos da Cartografia Social. }\end{array}$ & $\begin{array}{l}\text { Fórum e encontros de publicização } \\
\text { dos mapas munidos de discursos } \\
\text { esperançosos referentes à Cartografia } \\
\text { Social enquanto ferramenta de luta } \\
\text { comunitária. }\end{array}$ & \\
\hline
\end{tabular}

Quadro 1 - Etapas de elaboração dos mapas, objetivos, metas alcançadas e imagem.

\section{O MAPEAMENTO DOS CONFLITOS SOCIOAMBIENTAIS DO CAMPO EM APODI - RN}

O mapeamento foi construído sob o prisma da coletividade com a representação dos setores associados às diversas formas de uso do território camponês e vinculados com a espacialização de uma série de conflitos e injustiças socioambientais em seus ambientes do domínio das práticas tradicionais (agricultura 
familiar camponesa). O município de Apodi apresenta um dinamismo na medida em que se diferencia em quatro setores denominados por seus habitantes e que confluem com condições físico-naturais diferenciadas, a saber: Chapada; Pedra; Areia e Vale (Figura 1).

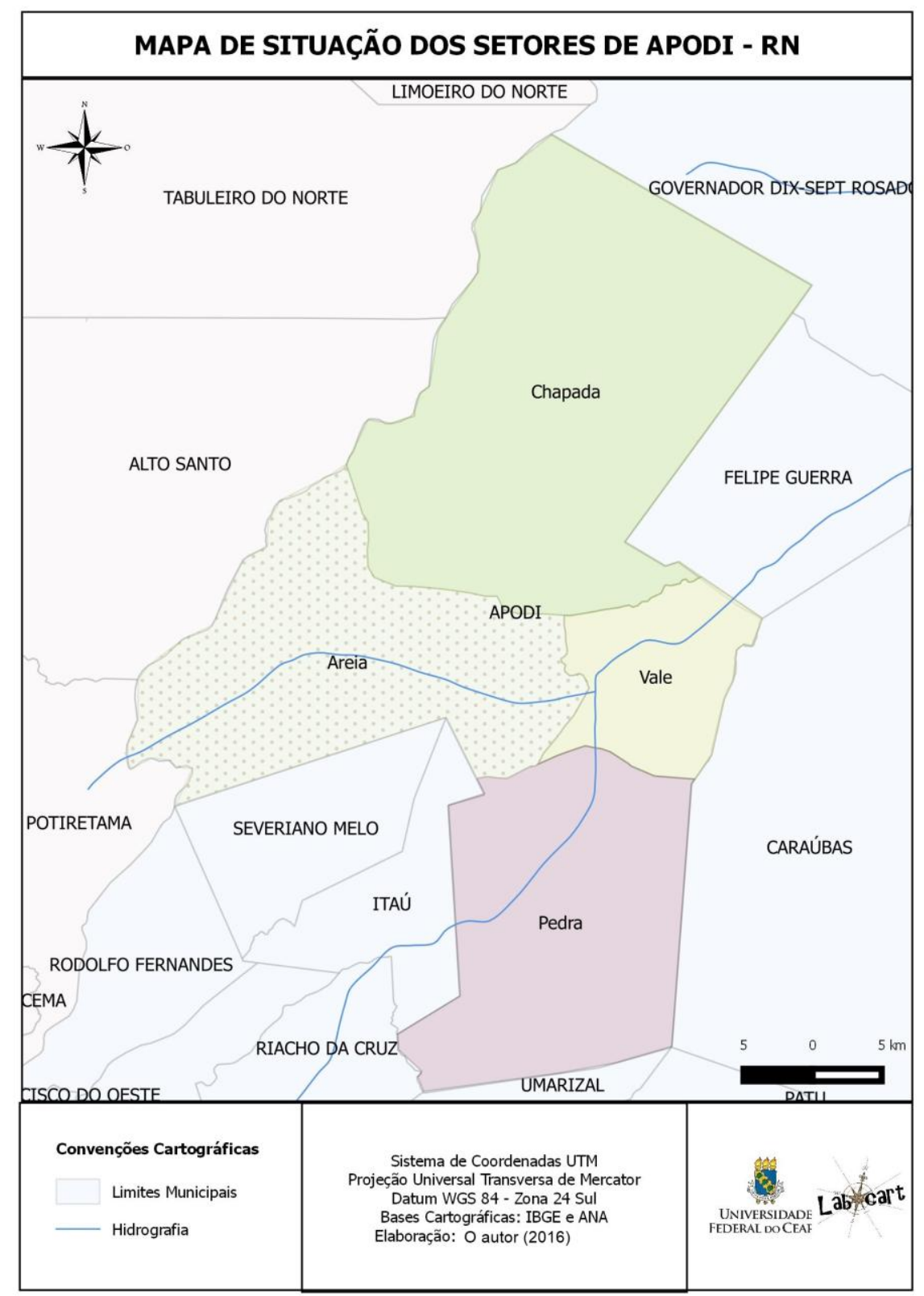

Figura 1 - Localização geográfica das regiões do município de Apodi - RN.

Respeitando tal diferenciação, o mapeamento social de Apodi foi organizado e planejado seguindo os limites e singularidades de cada setor. Assim sendo, como resultante do envolvimento de aproximadamente 400 sujeitos sociais, 
construíram 4 mapas regionais e 1 mapa geral propositivo, onde foram reunidas as propostas de cada um dos setores, mas pensando o território municipal, e reafirmando-o enquanto uma só unidade reivindicatória pela manutenção dos direitos sociais.

Convém ressaltar que os mapas elaborados durante as atividades formativas não serão apresentados neste trabalho tendo em vista que os produtos cartográficos devem passar por um processo de publicação pelos sujeitos sociais que participaram da confecção dos mapas. Optou-se por se trabalhar com a apresentação das legendas construídas pelo público alvo envolvido nas atividades de mapeamento

O mapa social da região da Chapada revela um dos conflitos socioambientais mais preocupantes em Apodi. Por seu solo potencialmente rico para a produção agrícola, grandes empresas multinacionais do agronegócio vislumbram e passam a ampliar seus negócios nesses espaços, comprando ou arrendando mais e mais terras. Essa expansão, de um modo de produção muito distinto do propagado pelos pequenos agricultores, causa danos à vida dos moradores locais não por somente invadirem seu mercado com condições desiguais de concorrência, mas por trazerem junto às suas instalações ameaças à vida e aos recursos naturais vitais, como o solo e as águas.

A legenda do mapa (Figura 2) revelou problemáticas que se configuraram no território após a chegada das grandes empresas, em contrapartida, destacaram a organização comunitária e as diversas culturas produtivas semeadas sem insumos ofensivos, refutando o discurso hegemônico de que as comunidades nada produzem e que não semeiam um modo de produção valoroso.

A Região da Areia é, talvez, a menos diretamente atingida por conflitos ambientais latentes. Suas problemáticas espacialmente reivindicadas no mapa centram-se mais nas condições de pouco acesso as políticas públicas para o pequeno produtor do campo e na preocupação das ameaças que assolam o território da chapada, mais diretamente relacionada à utilização de agrotóxicos e contaminação das águas superficiais e subterrâneas pelas agroindústrias de exportação, que tendem potencialmente a direcionar-se para este setor munidos por incentivos governamentais. A legenda do mapa (Figura 3) demonstra o anseio de mostrar a produção e organização social e comunitário do pequeno produtor do 

agronegócio.

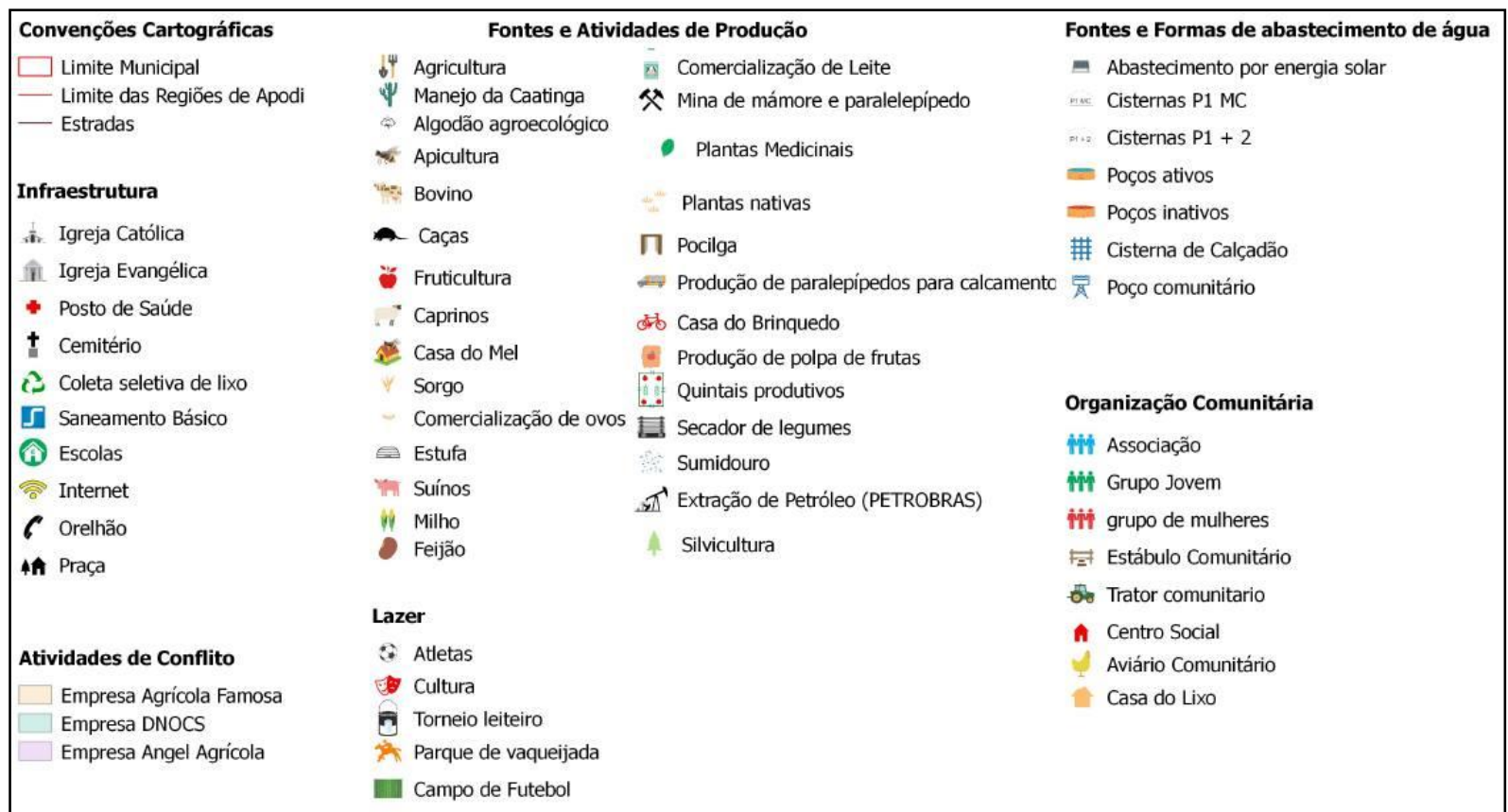

Figura 2 - Legenda do Mapa Social da Região da Chapada - Apodi - RN.

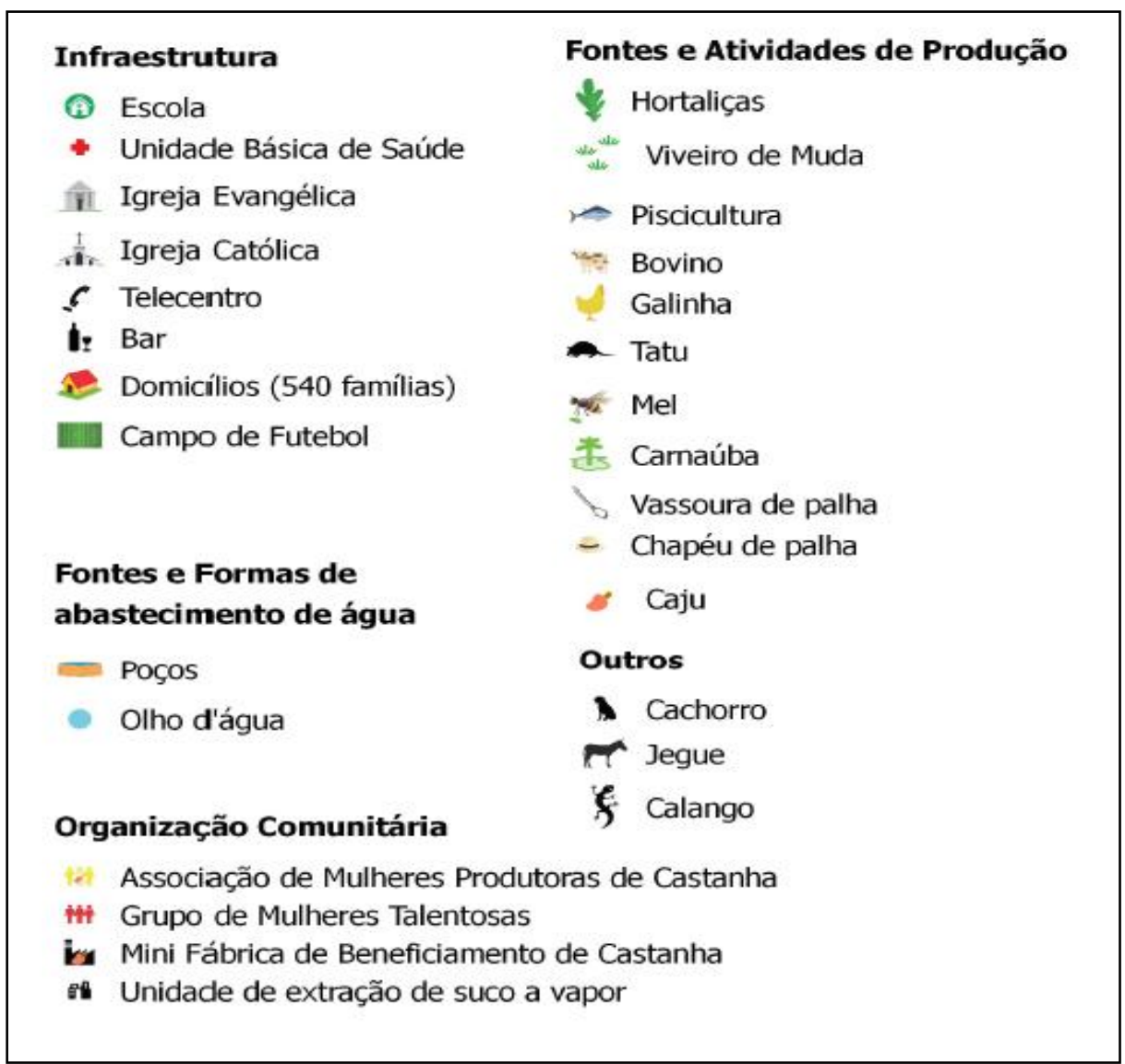

Figura 3 - Legenda do Mapa Social da Região da Areia - Apodi - RN 
Na região da Pedra, a grande problemática socioambiental centra-se no acesso à água. Como a nomenclatura da desse setor já esclarece, ela caracterizase ambientalmente por apresentar características semiáridas com grande quantidade de rochas em superfície (solos raros e pedregosos) fatores que junto à escassez hídrica do momento climático atual, dificultam o armazenamento de água (Figura 4).

Nessas condições, um fato em destaque no mapa foi a presença da Barragem Santa Cruz, que abastece municípios vizinhos e que está em planejamento de bombeamento de água para as empresas instaladas na Chapada, distanciando-se a poucos (15-18) quilômetros de comunidades com acesso muito escasso à água. Frente a isso, os agricultores e agricultoras mapeiam seus meios de organização comunitária, suas tecnologias de convivência com o semiárido e o que são/produzem quando o acesso à agua lhes é permitido (normalmente nos períodos chuvosos).

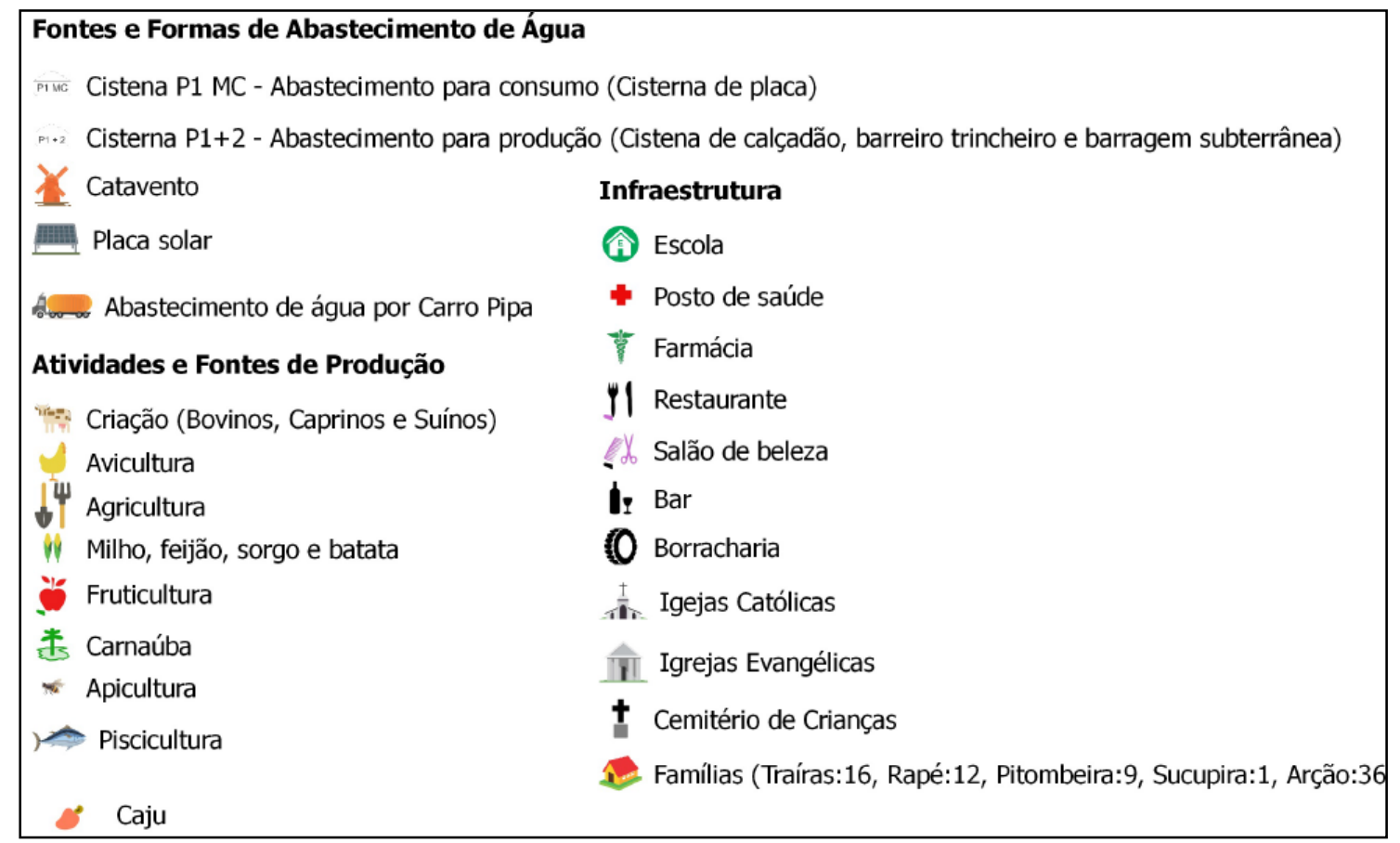

Figura 4 - Legenda do Mapa Social da Região da Pedra - Apodi - RN.

Na região do Vale também se acentuam problemáticas inerentes ao acesso à água, entretanto, em outras dimensões (Figura 5). A região é drenada pelo Rio Apodi, importante recurso hídrico para a pecuária e produção de diversos insumos pelos agricultores, destacando-se o arroz vermelho. Nesse quadro, o Rio Apodi (no 
trecho que mais se aproxima da Chapada) já se encontra em obra que objetiva seu barramento para direcionar as águas às grandes empresas presentes na Chapada.

Concomitantemente, os agricultores e agricultoras do Vale foram notificados por não possuírem o documento jurídico que lhes concede o direito ao uso da água, a outorga. Mais uma vez, o pequeno produtor sofre frente às condições e consequências desiguais aos grandes empreendimentos, uma vez que não há impedimento para o uso da água pelos empresários do agronegócio.

\begin{tabular}{|c|c|c|}
\hline \multicolumn{2}{|c|}{ Convenções Cartográficas } & Infraestrutura \\
\hline \multirow{5}{*}{\multicolumn{2}{|c|}{$\begin{array}{l}\square \text { Limite Municipal } \\
- \text { Limite das Regiões de Apodi } \\
\text { — } \text { BR-405 } \\
\text { - Estradas } \\
\text { - Drenagem } \\
\square \text { Corpos d'agua }\end{array}$}} & (1) Escola \\
\hline & & Escola Fechada \\
\hline & & th Igreja \\
\hline & & Quadra Esportiva \\
\hline & & Fontes e formas de abastecimento de água \\
\hline \multicolumn{2}{|c|}{ Fontes e atividades de produção } & - Barreiro \\
\hline Acerola & Yin Porco & $\hat{\rho}_{1+2}$ Cisterna \\
\hline V Arroz & & - Poço Comunitário \\
\hline Y Banana & V Sorgo & - Poço Seco \\
\hline$\Rightarrow$ Banco de Sementes & $V=$ Vaca & $=$ Poço sem Outorga \\
\hline Batata Doce & C Camarão & - Poço Usado \\
\hline $\begin{array}{l}\text { Criatório de Peixe } \\
\text { Feiãa }\end{array}$ & 迷 Carnauba & 觜 Caixa D'agua \\
\hline Galinha & Q Coco & Organização Comunitária \\
\hline $\begin{array}{ll} & \text { Leite } \\
\text { Milho }\end{array}$ & - Plantas Medicinais & irit Grupos \\
\hline * Ovelha & * Cajú & Casa do Artesanato \\
\hline$\because$ Ovos & & Casa do Mel \\
\hline
\end{tabular}

Figura 5 - Legenda do Mapa Social da Região da Vale - Apodi - RN

A construção de cartografias sociais envolve significados que vão além da mera representação física das problemáticas e potencialidades do território. Pela organização comunitária que seu processo necessita, ela passa a significar também momentos de fortalecimento da união e resistência frente às questões socioambientais desiguais e potencializando a busca pela garantia de direitos. Sobre esse aspecto, Gorayeb; Meireles; Silva (2015, p.18) asseguram que,

A metodologia de construção dos mapas possibilita um planejamento participativo em várias esferas de atuação, uma vez que a atitude de 
mapear as ações, os objetos e os processos resultam em uma maior reflexão em grupo do cotidiano e de sua práxis, possibilitando o exercício de atitudes cidadãs.

Nesse sentido, nota-se a dimensão reflexiva que os mapas passam a representar. Tal dimensão, reflete-se na elaboração de um mapa geral propositivo, servindo como subsídio aos grupos mapeadores na elaboração de ações propositivas frente ao que se problematiza, munindo-os não apenas materialmente, mas politicamente. As propostas elencadas pelos sujeitos individualizam-se em cada região, dispostas resumidamente a seguir:

Ações Propositivas da Região de Areia - Produção de ração animal tendo como matéria prima o caju / aumentar o plantio da palma forrageira / aproveitamento do caju (doces, compotas, poupas, suco) / quadra de esporte / praça para juventude.

Ações Propositivas da Região da Pedra - Sistema de abastecimento de água para consumo e produção / aumentar a quantidade de água distribuída por carros pipa em período de estiagem (medida emergencial) / continuação da construção da Unidade Básica de Saúde - UBS / reforma e construção de novas casas / regularização do selo SIM / Posto policial na comunidade de melancias / acesso ao crédito PAA e PNAF / Abatedouro de animais / capacitação e acompanhamento de aos produtores de animais e da agricultura familiar.

Ações Propositivas da Região do Vale - Perenização do rio Umari / Unidade de Beneficiamento de Frutas nas comunidades Baixa Verde I e II / acesso ao DAP para a juventude / assistência técnica e extensão rural em Baixa Verde I, II e em Água Fria / reforma e reativação do centro comunitário da comunidade Água Fria / educação contextualizada no campo/ adaptação de cursos do Instituto federal a realidade do campo / projetos voltados à reforma e construção de casas / construção de poços nas comunidades de Baixa Verde I e II / coleta seletiva de lixo / iluminação pública / escola em Baixa Fechada I / comercialização dos produtos da comunidade de Água Fria / trazer a escola técnica Jundiaí para Água Fria / Reativar projeto Dom Helder.

Ações Propositivas da Região da Chapada - Acesso ao crédito bancário destinado à produção e geração de renda na comunidade de Cruzeiro / ampliar a adura municipal até a comunidade de Cruzeiro / reativação das dos poços presentes nas comunidades de Cruzeiro e Soledade / construção de um poço na comunidade 
de Moacir Lucena / construção de uma unidade de beneficiamento de leite para a região da chapada / construção de um poço para irrigação na comunidade de Aurora / escola de ensino fundamental e médio na comunidade Sitio do Góis / espaço adequado para a rádio comunitária presente em Sitio do Góis / recapeamento das estradas e calçamento nas comunidades / divulgação dos dados da agricultura familiar / apoio para a realização do torneio leiteiro no sitio do Góis / fortalecimento do manejo da caatinga / coleta seletiva no sitio do Góis.

Dessa forma, a Cartografia Social configura-se enquanto mecanismo e instrumento que busca a promoção da justiça ambiental ou que auxilie essa busca, refutando a "imposição desproporcional dos riscos ambientais às populações menos dotadas de recursos financeiros, políticos e informacionais" (ACSELRAD; MELLO; BEZERRA, 2009, p.9)

\section{CONSIDERAÇÕES FINAIS}

As ações referentes à Cartografia Social realizadas junto aos agricultores e agricultoras do município de Apodi procuraram promover múltiplos momentos de reflexão, debate e a construção participativa de mapas acerca das realidades socioambientais presentes no campo, levando em consideração as percepções dos sujeitos que conhecem seus territórios e os problemas, conflitos, potencialidades que nele se delineiam.

A construção coletiva e participativa dos mapas, além de proporcionar novas reflexões relativas às dimensões que a Ciência Cartográfica vem tomando, constrói uma relevância aplicada referente ao subsídio que ela vem representando aos povos e comunidades tradicionais na instrumentalização na busca pela garantia de direitos e justiça ambiental.

Nesse sentido, entende-se a Cartografia Social enquanto potencial ferramenta de gestão do território, além de materializar-se enquanto representação do acesso ampliado das tecnologias aos povos do campo, visibilizando-os através de sua autocartografia diante das ameaças de acesso à água, à terra e à vida que se ampliam em seus territórios. 


\section{Referências}

ACSELRAD, H; COLI, L.R. Disputas cartográficas e disputas territoriais. In: ACSELRAD, $H$. et al. (Org.). Cartografias sociais e território. Rio de Janeiro: Universidade Federal do Rio de Janeiro, Instituto de Pesquisa e Planejamento urbano e Regional, 2008, p. 13-43.

Asociación de Proyetos Comunitarios - POPAYAN. Territorio y Cartografia Social. Proyecto: Fortalecimiento de las organizaciones pertenecientes a la asociacion de proyectos comunitarios. a.p.c. 2005. p.1-9. Disponível em: http://www.rutapedagogicaamigoniana.org/documentos/materiales/Modulo_0_Territo rio.pdf . Acesso em 05 de maio de 2015.

ACSELRAD, H; MELLO, C. C. A; BEZERRA, G. N. O que é Justiça Ambiental. Rio de Janeiro: Garamond, 2009. 160 p.

BARGAS, J. K. R; CARDOSO, L. F. C. Cartografia social e organização política das comunidades remanescentes de quilombos de Salvaterra, Marajó, Pará, Brasil. Bol. Mus. Pará. Emílio Goeldi. Cienc. Hum., Belém, v. 10, n. 2, 2015, p.469-488.

CUBIDES, A. H. Y. P. La Cartografia Social como instrumento metodológico em los procesos de construción de territorio a parti de la participación ciudadana em la planeación territorial y la construción del espacio público. (Tesis de maestría). Universidad Pontificia Javeriana, 2009 163p.

GorAYEB, A; MEIRELES, A. J. A; SILVA, E. V. Princípios básicos de Cartografia e Construção de Mapas Sociais. In: GORAYEB, A; MEIRELES, A. J. A; SILVA, E. V (Org.). Cartografia Social e Cidadania: experiências de mapeamento participativo dos territórios de comunidades urbanas e tradicionais. Fortaleza: Expressão Gráfica Editora, 2015. P. 9 -24.

AUBRY, A. Otro modo de hacer ciencia. Miseria y rebeldía de las ciencias sociales. In: BARONNET, B; BAYO, M. M; STAHLER-SHOLK, R. Luchas "Muy Otras" Zapatismo y autonomia en las Comunidades Indígenas de Chiapas. Cayoacán: Universidad Autónoma Metropolitana, 2011, 59-78p. 